\title{
EFFECTS OF ADRENERGIC BLOCKADE ON THE PULMONARY CIRCULATION IN MAN
}

\author{
BY \\ S. H. TAYLOR, G. J. MACKENZIE, M. GEORGE, AND A. MCDONALD \\ From the University Department of Medicine, The Royal Infirmary, Edinburgh \\ Received August 7, 1964
}

Though the pulmonary blood vessels appear to be abundantly supplied with autonomic neurones from both the sympathetic and parasympathetic nervous systems, the functional activities of these fibres in man continue to elude precise definition. Equally obscure is the part played in the maintenance of normal pulmonary vascular tone by the endogenous circulating catecholamines.

In this latter respect, previously reported studies, which appear to have been entirely concerned with the effects of adrenergic blocking agents in patients suffering from severe pulmonary vascular diseases, have yielded largely irreconcilable results. Further, there appear to be no reports of the effect of these drugs on the systemic venous pressure of man. The present report, part of a larger study of the over-all circulatory effects of one of these agents, phentolamine, concerns an analysis of the effects of this drug on the pulmonary and venous circulations of normal subjects and of patients suffering from hypertensive vascular disease.

\section{SubJeCtS AND MeTHOdS}

Clinical Data. Studies were made on 6 normal subjects and 6 hypertensive patients; details of each are listed in Table I.

All the hypertensive patients were considered to be suffering from essential hypertension on the basis of the usual diagnostic clinical criteria. None had any symptoms referable to the cardiovascular system except patient A.A., who had mild exertional dyspnœa. In 5 of the 6 patients the resting diastolic pressure, recorded in the supine position, exceeded $120 \mathrm{~mm}$. Hg. In 4 of the hypertensive patients (E.B., J.W., J.N., and F.E.) there was no radiological or electrocardiographic evidence of left ventricular enlargement. In the remaining 2 patients there was radiological evidence of cardiac hypertrophy without dilatation and in both instances this was associated with electrocardiographic changes indicative of moderate left ventricular hypertrophy. The optic fundi were without papillœdema, hæmorrhages, or exudates in all 6 hypertensive patients; routine tests of renal function were also within normal limits and arteriographs showed no evidence of renal vascular disease. The 24-hour urinary excretion of vanillylmandelic acid was within normal limits in all the hypertensive patients.

Plan of Investigation. The investigation was designed to study the changes occurring in the pulmonary circulation following the abrupt intravenous injection of phentolamine in the dose usually used in clinical diagnostic procedures. In all individuals pulmonary arterial and wedge pressures, systemic arterial and right atrial pressures, cardiac output, and heart rate were measured during a control period of 10 minutes and then for a further 30 minutes following the rapid intravenous injection of $5 \mathrm{mg}$. phentolamine in a volume of $2 \mathrm{ml}$; the injection was completed within two seconds.

All vascular pressures and heart rate were recorded continuously throughout the study. Cardiac output was determined on alternate minutes during the control period, every minute for the 6 minutes after injection of the drug, and then on alternate minutes again for the remainder of the study.

The injection of phentolamine ( 2 - (N-p-tolyl-N-m-hydroxyphenylamino-methyl) - imidazoline) was given as the methane sulphonate salt. 
TABLE I

Details of Normal SubJects and Hypertensive Patients Studied

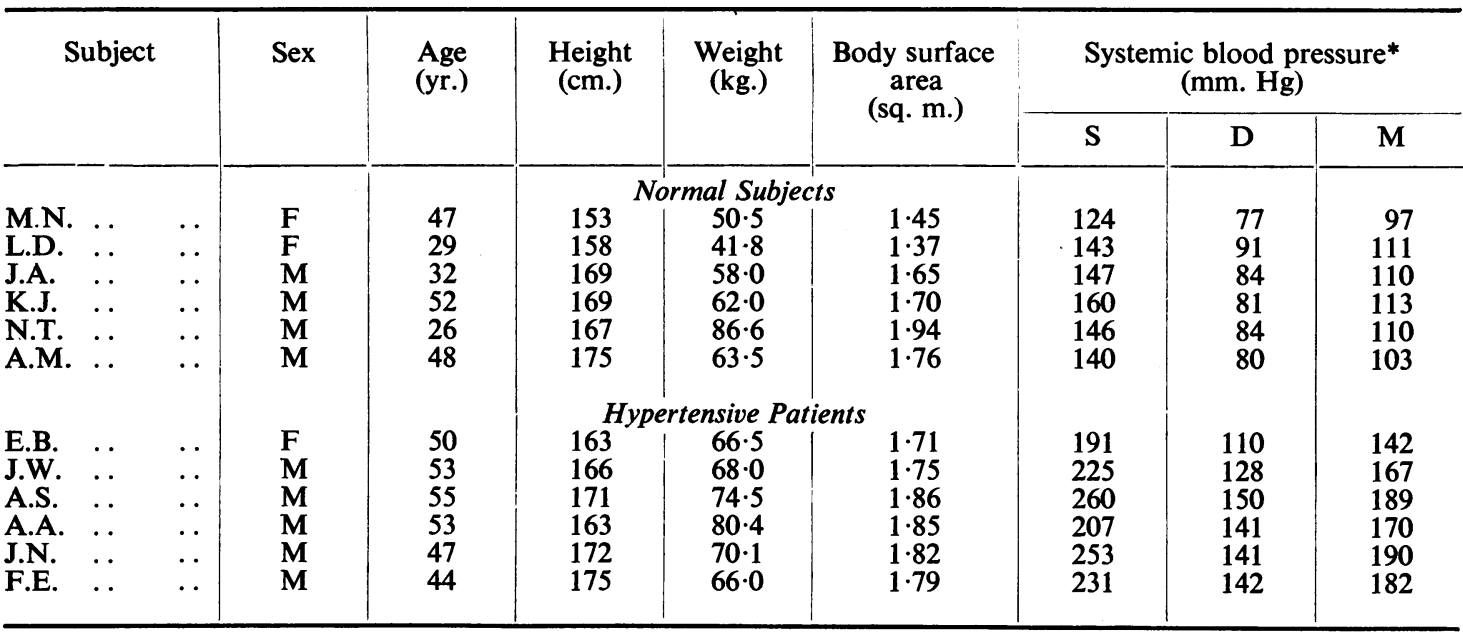

* Values given for the systemic blood pressure are the average of those recorded at the time of the study during the initial resting period before injection of the phentolamine.

Laboratory Techniques. Laboratory air temperature was controlled at $23^{\circ} \mathrm{C}$. in all studies; the relative humidity varied between 50 and 70 per cent.

The patients were first familiarized with the procedure, the laboratory surroundings, and the personnel involved and were then studied in the supine position, fasting, and without sedation. Previous studies have demonstrated that a more basal and stable circulatory state may be induced in patients under investigation by a short period of non-fatiguing leg exercise (Taylor et al., 1962). In the present study, a 5-minute period of light leg exercise was given 20 minutes before the control observations.

Systemic arterial pressure was taken through a nylon catheter, bore $0.8 \mathrm{~mm}$., length $55 \mathrm{~cm}$. , introduced percutaneously into the brachial artery by a modified Seldinger technique and advanced into the aortic root. Pressures were transduced by a Statham P23Db strain gauge manometer. The saline-filled calibration pressure heads for the system were maintained by specially calibrated Reckla aneroid manometers.

Pulmonary arterial, wedge, and right atrial pressures were taken through a triple lumen catheter and transduced by Statham P23Db strain gauge manometers. Venous manometers were calibrated against an open saline column. Zero reference level of all manometers was $10 \mathrm{~cm}$. above the plane of the x-ray table and all manometer pressure heads were fixed at this level. The electrical output from each manometer was arranged to allow synchronous recording of both pulsatile and mean pressures.

Cardiac output was determined by an indicator dilution technique employing indocyanine green. Precisely known amounts of the dye, approximately $2 \mathrm{mg}$. in $1.5 \mathrm{ml}$. volume, were injected into the main stem of the pulmonary artery just beyond the pulmonary valve through one lumen of a second triple lumen cardiac catheter by a rapid action, electrically activated, compressed air-driven syringe-pump, each injection being completed within $0.3 \mathrm{sec}$. The dye dilution curves were taken from the aortic root through a second arterial catheter of identical dimensions to that used for arterial pressure measurement. Blood was withdrawn through the cuvette at a sampling rate of $38 \mathrm{ml}$. per minute by a constant speed syringe-type Harvard pump. The dye curves were transcribed by a Waters X300A cuvette densitometer in conjunction with an ultraviolet type recorder. By this technique, duplicate determinations of cardiac output, carried out under strictly controlled conditions of circulatory stability, have been shown to differ by less than 4 per cent. The standardization and precision of this dye dilution method are being reported elsewhere (Taylor et al., 1965b). The heart rate was determined from a continuously recorded electrocardiographic trace.

All analogue tracings were recorded on a multichannel ultraviolet recorder (New Electronic Products Ltd., Type 1185) using galvanometers of $35 \mathrm{~cm}$. focal length and a distortion-free deflection arc of $10 \mathrm{~cm}$., arranged as previously described (Taylor et al., 1962). The frequency response of the galvanometers used for recording the intravascular pressures was 90 cycles per second at 95 per cent of true fidelity.

Measurements and Calculations. Intravascular pressures and heart rate were measured as the average 
of the 15-second values falling equally about the definitive point. Cardiac outputs were measured by conventional integration techniques, the final 10 per cent only of the downslope requiring to be replotted according to the Hamilton semilogarithmic extrapolation method. The cardiopulmonary blood volume was calculated according to the Hamilton formula; the mean transit time was corrected for a time delay of 1.6 seconds in the catheter-cuvette sampling system. The calculation of the mean pulmonary vascular resistance was modified to incorporate a correction for the body surface area, the arguments for which have been discussed elsewhere (Taylor et al., 1962). Statistical analyses were based on orthodox methods (Fisher, 1946). Description of the significance of changes due to the drug were based on the method of comparison of differences between the means of small samples. In the present study, the statistical significances given for each parameter relate to the differences between the average of the values in the control period and the single value at the stated time.

\section{ResULTS}

The individual values of the primary measurements and derived data are illustrated in Fig. 1-10. The percentage differences between the average control value and that obtaining at the second minute after injection of the drug for each parameter in each subject are summarized in Table II.

Changes in Systemic Arterial Pressure. The acute injection of phentolamine was immediately followed by an abrupt fall in systemic arterial pressure, the maximum fall occurring within one minute in all subjects. The average reduction in mean arterial pressure was $15 \mathrm{~mm} . \mathrm{Hg}$ (range of reduction 13-20) and $34 \mathrm{~mm} . \mathrm{Hg}$ (range of reduction 18-55) in the normal subjects and hypertensive patients, respectively. Subsequently, the systemic blood pressure gradually returned towards preinjection control values in all subjects. These changes have been described in detail elsewhere (Taylor et al., 1965d).

Changes in Cardiac Output. The immediate fall in systemic arterial pressure was followed by a somewhat less prompt increase in cardiac output. The maximum increase in cardiac output

TABLE II

Percentage Changes Between Average Control Value and 2nd Minute After Phentolamine InJection

\begin{tabular}{|c|c|c|c|c|c|c|c|}
\hline \multirow[t]{2}{*}{ Subject } & \multicolumn{5}{|c|}{ Vascular pressures $(\%)$} & \multirow{2}{*}{$\begin{array}{l}\% \\
\text { Cardiac } \\
\text { output }\end{array}$} & \multirow{2}{*}{$\begin{array}{c}\% \\
\text { Pulm. vasc. resist. }\end{array}$} \\
\hline & MAP & PW & PA & $\Delta \mathbf{P}$ & RA & & \\
\hline $\begin{array}{l}\text { M.N. } \\
\text { L.D. } \\
\text { J.A. } \\
\text { K.J. } \\
\text { N.T. } \\
\text { A.M. }\end{array}$ & $\begin{array}{r}-19 \\
-8 \\
-12 \\
-8 \\
-11 \\
-12 \\
\end{array}$ & $\begin{array}{l}-38 \\
-38 \\
-29 \\
-89 \\
-57 \\
-50 \\
\end{array}$ & $\begin{array}{l}{ }^{13} \\
-31 \\
-15 \\
-38 \\
-45 \\
-40 \\
\end{array}$ & $\begin{array}{c}\text { nal Subj } \\
-14 \\
-20 \\
0 \\
-12 \\
-25 \\
-29\end{array}$ & $\begin{array}{r}-100 \\
-100 \\
-100 \\
-75 \\
-100 \\
-100\end{array}$ & $\begin{array}{l}+23 \\
+30 \\
+12 \\
+10 \\
+14 \\
+20\end{array}$ & $\begin{array}{l}-31 \\
-38 \\
-24 \\
-17 \\
-47 \\
-40\end{array}$ \\
\hline $\begin{array}{l}\text { Mean } \\
\text { S.E. of mean } \\
p\end{array}$ & $\begin{array}{c}-12 \\
1.65 \\
<0.001\end{array}$ & $\begin{array}{c}-50 \\
8.76 \\
<0.01\end{array}$ & $\begin{array}{r}-30 \\
5.48 \\
<0.01\end{array}$ & $\begin{array}{r}-17 \\
4.24 \\
<0.02\end{array}$ & $\begin{array}{c}-96 \\
4 \cdot 17 \\
<0.001\end{array}$ & $\begin{array}{c}+18 \\
3 \cdot 10 \\
<0.01\end{array}$ & $\begin{array}{c}-33 \\
4.51 \\
<0.001\end{array}$ \\
\hline $\begin{array}{l}\text { E.B. } \\
\text { J.W. } \\
\text { A.S. } \\
\text { A.A. } \\
\text { J.N. } \\
\text { F.E. }\end{array}$ & $\begin{array}{r}-8 \\
-20 \\
-21 \\
-12 \\
-9 \\
-18\end{array}$ & $\begin{array}{c}-50 \\
-57 \\
-50 \\
-25 \\
0 \\
-56\end{array}$ & $\begin{aligned} & H y \\
&-33 \\
&-24 \\
&-48 \\
&-24 \\
&-6 \\
&-41\end{aligned}$ & $\begin{array}{c}\text { ensive } p \\
-14 \\
0 \\
-47 \\
-23 \\
-17 \\
-25\end{array}$ & $\begin{array}{r}\text { nts } \\
-100 \\
-100 \\
-100 \\
-67 \\
-100 \\
-80\end{array}$ & $\begin{array}{l}+34 \\
+19 \\
+31 \\
+34 \\
+26 \\
+22\end{array}$ & $\begin{array}{l}-38 \\
-16 \\
-60 \\
-42 \\
-34 \\
-38\end{array}$ \\
\hline $\begin{array}{l}\text { Mean } \\
\text { S.E. of mean } \\
p\end{array}$ & $\begin{array}{c}-15 \\
2 \cdot 34 \\
<0.01\end{array}$ & $\begin{array}{r}-40 \\
9.25 \\
<0.01\end{array}$ & $\begin{array}{c}-29 \\
6.05 \\
<0.01\end{array}$ & $\begin{array}{c}-21 \\
6.33 \\
<0.05\end{array}$ & $\begin{array}{r}-91 \\
5.84 \\
<0.001\end{array}$ & $\begin{array}{c}+28 \\
2.59 \\
<0.001\end{array}$ & $\begin{array}{r}-38 \\
5.77 \\
<0.01\end{array}$ \\
\hline
\end{tabular}

MAP $=$ mean aortic pressure $; \mathbf{P W}=$ pulmonary wedge pressure; $\mathbf{P A}=$ pulmonary arterial pressure; $\Delta \mathbf{P}=$ pulmonary pressure gradient; $\mathbf{R A}=$ right atrial pressure. 

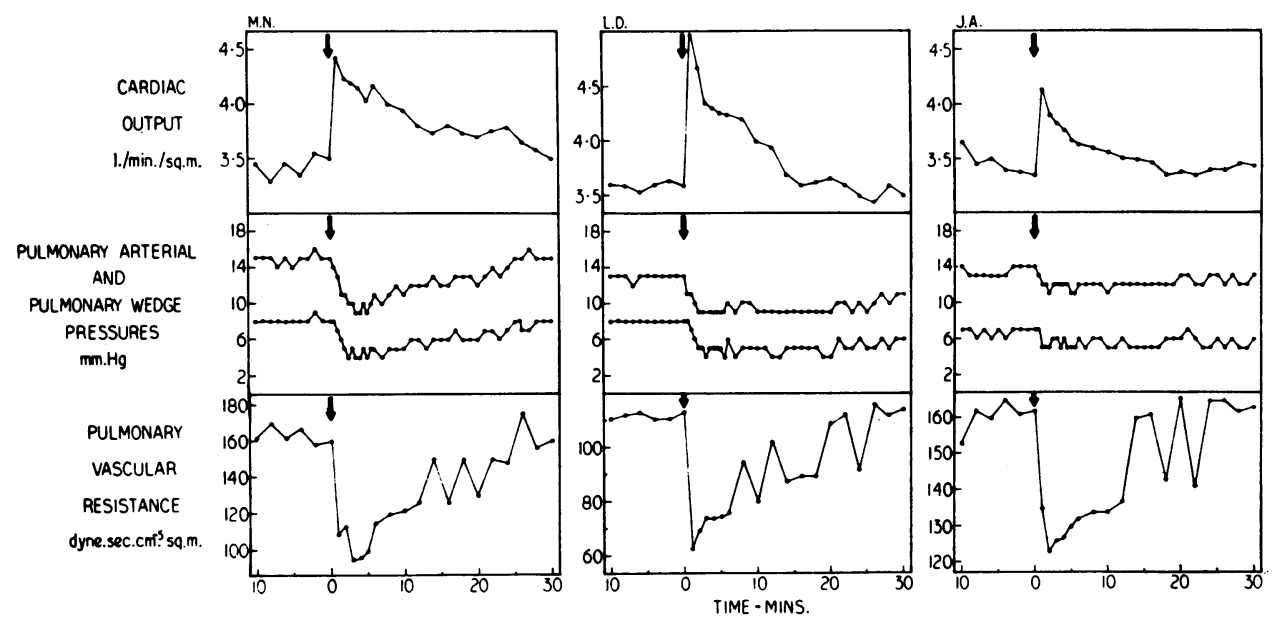

FIG. 1.-The effect of an acute intravenous injection of $5 \mathrm{mg}$. phentolamine on the pulmonary circulation of 3 normal subjects.
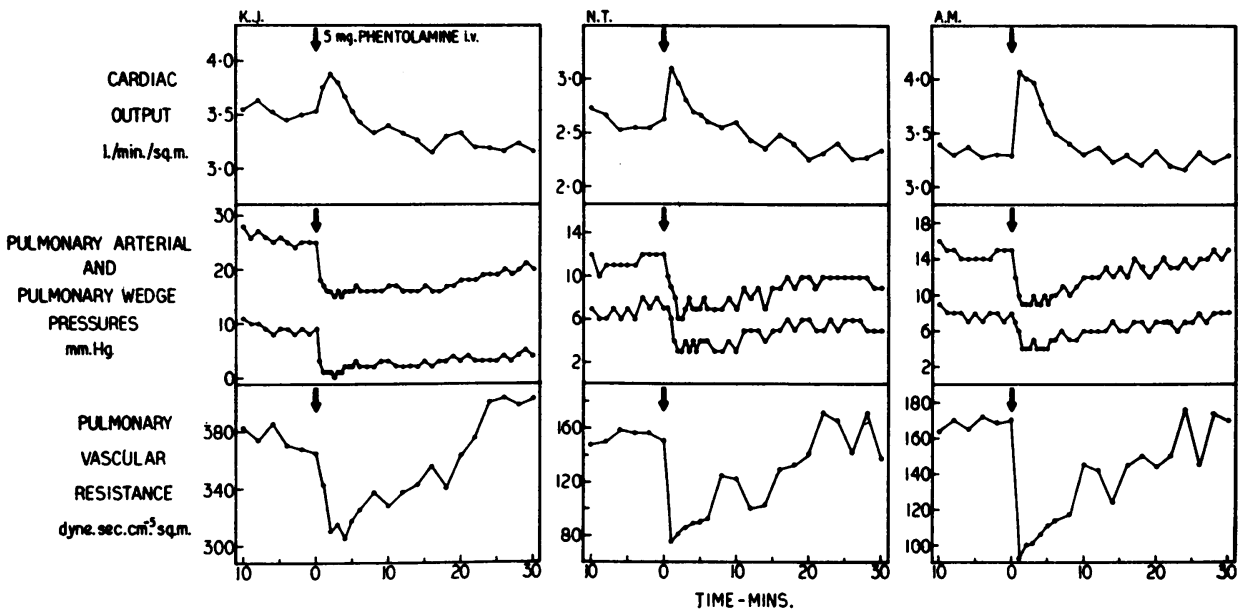

FIG. 2.-The effect of an acute intravenous injection of $5 \mathrm{mg}$. phentolamine on the pulmonary circulation of $\mathbf{3}$ normal subjects.

occurred within one minute in the normal subjects and within the first three minutes after the injection in all of the hypertensive patients (Fig. 1-4). The average maximum increases in cardiac output were $0.7791 . / \mathrm{min}$./sq.m. (range of increase $0.340-1.472 ; \mathrm{p}<0.010$ ) and 0.911 $1 . / \mathrm{min} . / \mathrm{sq} . \mathrm{m}$. (range of increase $0.725-1.184 ; \mathrm{p}<0.001$ ) in the normal and hypertensive groups respectively. The attainment of the peak increase in cardiac output was immediately succeeded by a gradual decrease, though the rate of return towards control values was much more rapid in the normal than in the majority of the hypertensive patients.

The changes in heart rate closely paralleled those of the cardiac output; they are described in detail elsewhere (Taylor et al., 1965d).

Changes in Pulmonary Vascular Pressures. The effect of the injection of $5 \mathrm{mg}$. phentolamine on the mean pulmonary arterial and wedge pressures in the six normal subjects is illustrated in Fig. 1 and 2. In 5 of the 6 normal subjects, the pulmonary arterial and wedge pressures measured during the control period were within normal limits $(17 \mathrm{~mm}$. $\mathrm{Hg}$ or less) with average values of 13 and 

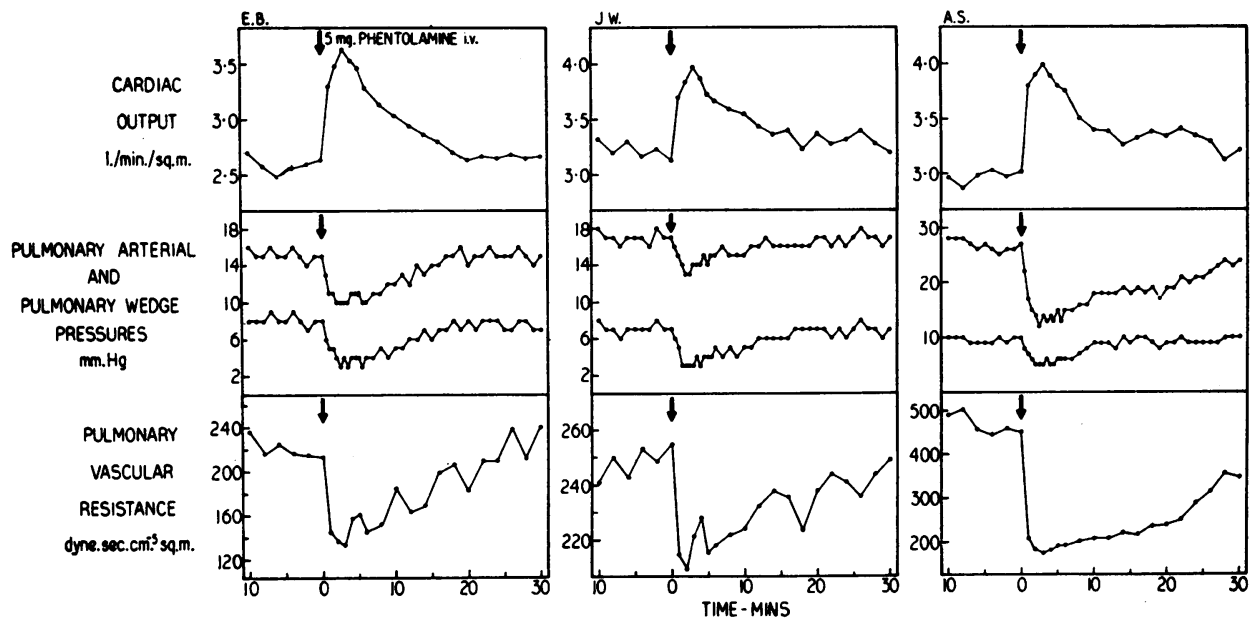

FIG. 3.-The effect of an acute intravenous injection of $5 \mathrm{mg}$. phentolamine on the pulmonary circulation of 3 hypertensive patients.
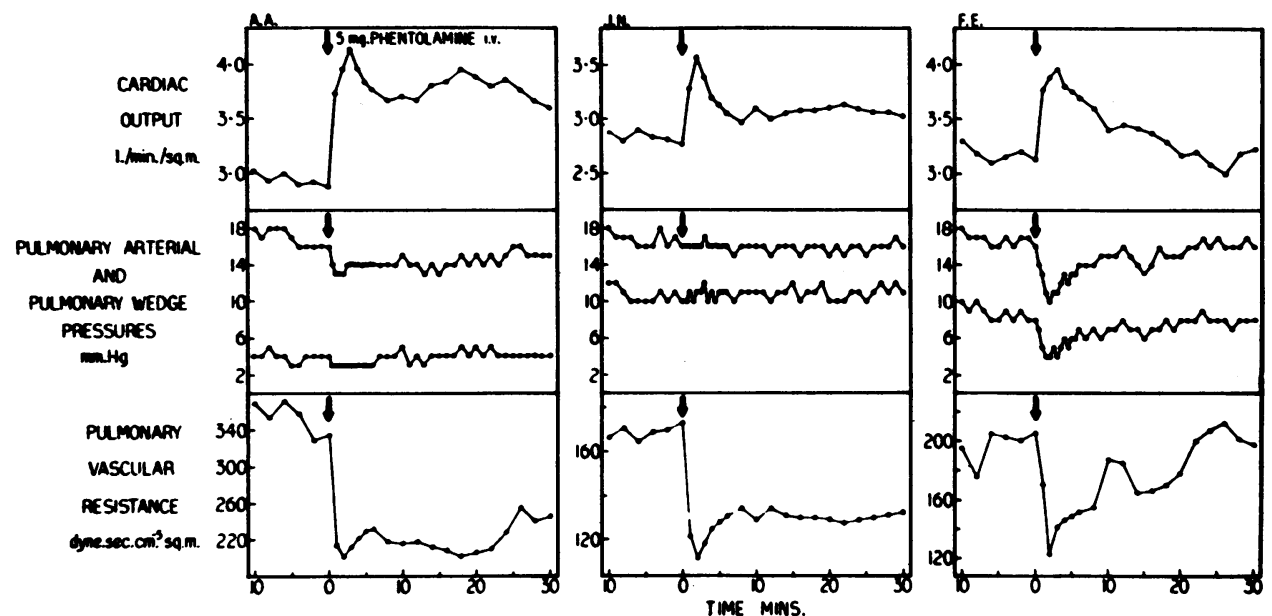

FIG. 4.-The effect of an acute intravenous injection of $5 \mathrm{mg}$. phentolamine on the pulmonary circulation of 3 hypertensive patients.

$8 \mathrm{~mm} . \mathrm{Hg}$ respectively. In the remaining subject (K.J.), the mean pulmonary arterial pressure was $26 \mathrm{~mm}$. $\mathrm{Hg}$; there was no recognizable clinical explanation for this raised pressure and the pulmonary wedge pressure was within normal limits at $9 \mathrm{~mm}$. $\mathrm{Hg}$. In all 6 subjects, the acute intravenous injection of the drug was immediately followed by a rapid decrease in pulmonary arterial and pulmonary wedge pressures; this was associated with a small reduction in the differential pressure gradient $(\Delta \mathrm{P})$ in all but one (J.A.) of the subjects. However, the reduction in the pulmonary vascular pressures occurred somewhat less rapidly than the fall in systemic arterial pressure. Whereas the maximum reduction in the systemic blood pressure occurred within the first minute after the injection in all subjects, the maximum fall in the pulmonary pressures was usually delayed until the second or third minutes after the drug. At the second minute after the injection, the average decreases in pulmonary arterial, wedge, and differential pressures were 30,50 , and 17 per cent respectively: all were statistically significant at the 2 per cent level of probability (Table II). Subsequently, the pulmonary pressures gradually increased towards pre-injection values, though 
they were still appreciably reduced in three subjects at the end of the period of observation, 30 minutes after the injection.

The injection of the drug resulted in very similar changes in the pulmonary arterial and wedge pressures in the 6 hypertensive patients to those observed in the normal subjects (Fig. 3 and 4). The control pulmonary arterial pressure was within normal limits in 5 of the 6 patients and the wedge pressure was normal in all. There was no clinically obvious reason apparent to explain the raised pulmonary arterial pressure in the remaining patient (A.S.). The injection of phentolamine was immediately followed by a considerable reduction in both of the pulmonary pressures in 5 of the 6 patients; this was accompanied by a small reduction in the pressure gradient $(\Delta P)$ in all. In the remaining patient (J.N.) the drug caused no appreciable change in either pressure. A similar time lag in the reduction in the pulmonary pressures was observed in these patients to that noted in the normal subjects. At the second minute after the injection the average decreases in pulmonary arterial, wedge, and differential pressures were 29,40 , and 21 per cent, respectively, values very similar in degree and level of statistical significance to those observed in the normal subjects. Subsequently, the pulmonary pressures gradually reverted towards pre-injection levels which were achieved in all patients within the period of observation.

Changes in Pulmonary Vascular Resistance. The changes in the mean pulmonary vascular resistance (PVR) in the 6 normal subjects followed a consistent pattern (Fig. 1 and 2). The control values were within normal limits (less than 250 dyne.sec.cm. ${ }^{-5}$ sq.m.) in 5 of the 6 subjects; in the remaining subject (K.J.) there was no apparent clinical cause for this increased resistance. The rapid intravenous injection of phentolamine was followed by an abrupt reduction in the PVR in all 6 subjects; compared with the control values, the average reduction at the second minute after the injection was 33 per cent $(\mathrm{p}<0.001)$. Following this initial fall, the PVR gradually increased towards pre-injection levels which were attained within 30 minutes in all 6 subjects.

The changes in the PVR in the 6 hypertensive patients followed an essentially similar pattern to that observed in the normal subjects (Fig. 3 and 4). The control values were within normal limits in 4 of the 6 patients. In the remaining 2 patients (A.S. and A.A.) there was no clinically apparent reason for the raised PVR. The rapid intravenous injection of the drug was immediately followed

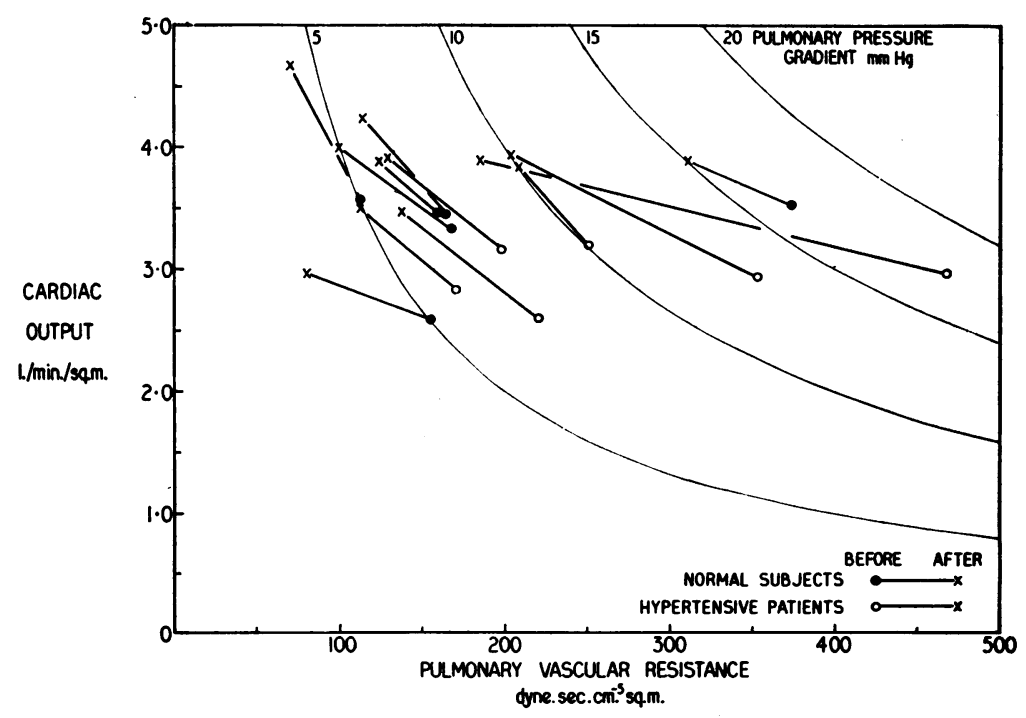

Fig. 5-The relative contribution of changes in cardiac output and pulmonary vascular resistance to changes in the pulmonary pressure gradient following the intravenous injection of phentolamine. 


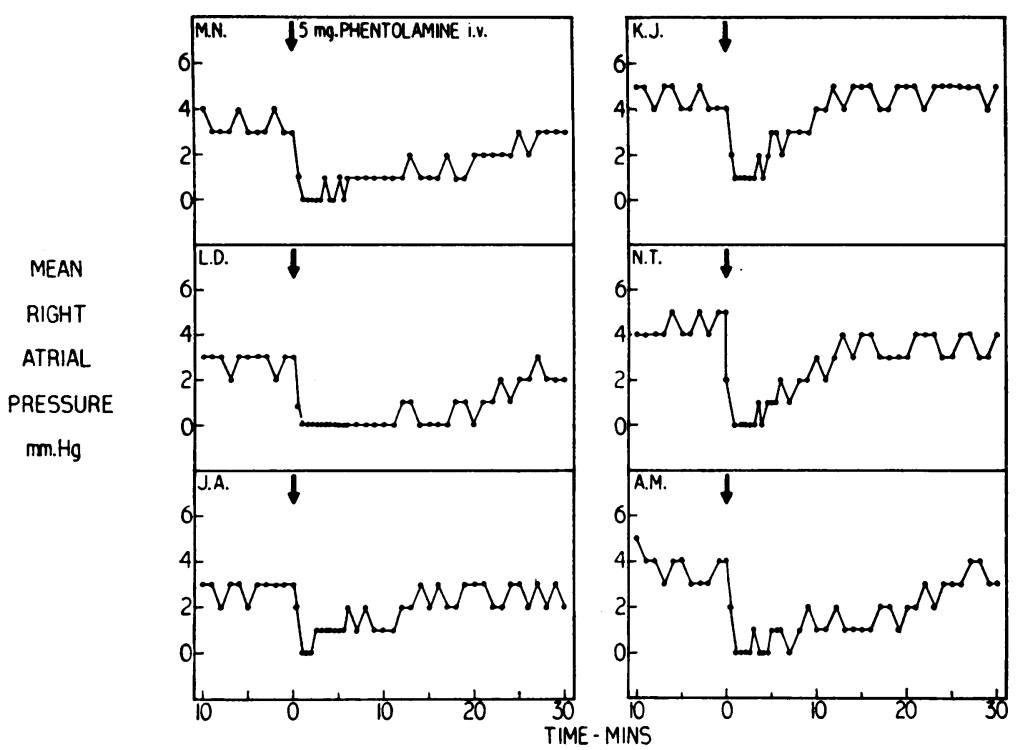

FIG. 6.-The effect of an acute intravenous injection of $5 \mathrm{mg}$. phentolamine on the right atrial pressure of 6 normal subjects.

by a prompt reduction in the PVR in all patients; compared with the control values the average reduction at the second minute after the injection was 38 per cent $(\mathrm{p}<0.01)$, a reduction very similar to that observed in the group of normal subjects. Following this abrupt fall, the PVR subsequently gradually increased towards pre-injection values, though it was still appreciably reduced in 3 patients at the end of the period of observation.

The relative contribution of changes in cardiac output and pulmonary vascular resistance to the associated changes in the pulmonary pressure gradient in each subject is displayed graphically in Fig. 5. Although the fall in PVR seen in those patients with normal control values was largely

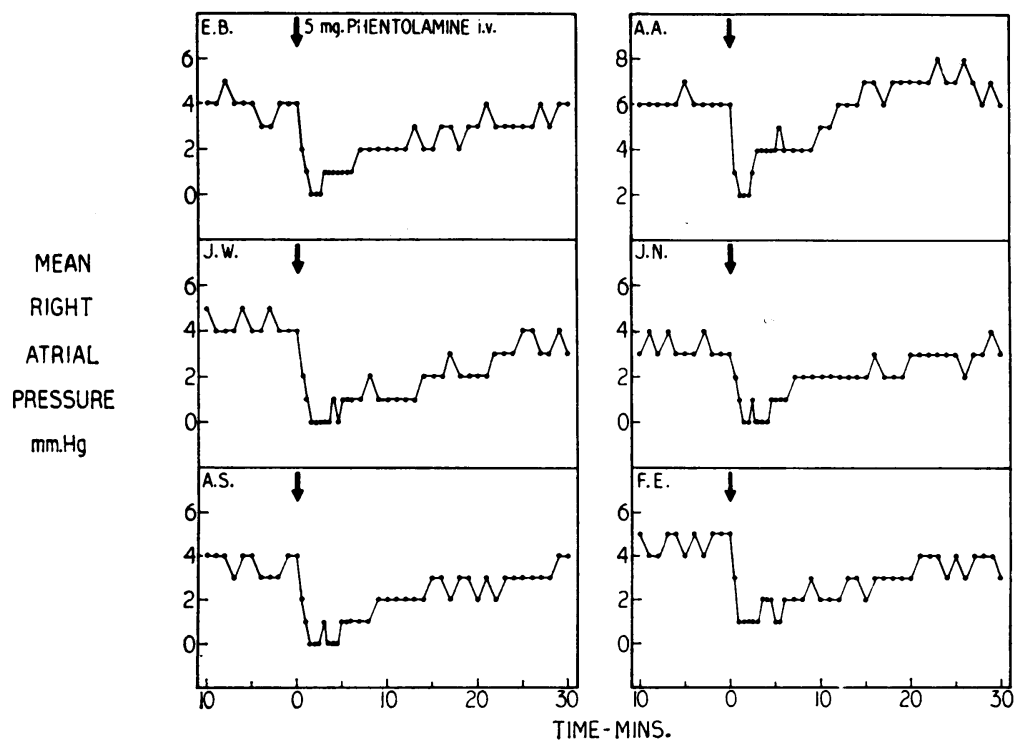

FIG. 7.-The effect of an acute intravenous injection of $5 \mathrm{mg}$. phentolamine on the right atrial pressure of 6 hypertensive patients. 
accounted for by a corresponding increase in cardiac output, the majority showed a small and statistically significant reduction in the pulmonary pressure gradient. This reduction in $\Delta \mathrm{P}$ was very much more marked in the one normal subject (K.J.) and two hypertensive patients (A.S., A.A.) in whom the pulmonary pressure gradient was initially raised; in these subjects the injection of phentolamine reduced the gradient largely by a reduction of PVR.

Changes in Right Atrial Pressure. The changes in mean right atrial pressure following the injection of phentolamine were essentially similar in both groups of subjects (Fig. 6 and 7). The average pre-injection control values were $4 \mathrm{~mm} . \mathrm{Hg}$ (range 3-4) and $4 \mathrm{~mm}$. $\mathrm{Hg}$ (range 3-6) in the normal and hypertensive groups of subjects respectively. The acute injection of the drug was immediately followed by a very considerable reduction in the right atrial pressure in all subjects, the maximum fall in pressure invariably occurring within the first two minutes. The average reduction at the second minute after the injection was $3 \mathrm{~mm} . \mathrm{Hg}(\mathrm{p}<0.001)$ and $4 \mathrm{~mm} . \mathrm{Hg}(\mathrm{p}<0.001)$ in each group respectively. Following this initial fall in right atrial pressure, the reduction was maintained for a few minutes, after which it increased gradually towards pre-injection levels in all subjects.

Changes in Cardiopulmonary Blood Volume. The changes that occurred in cardiopulmonary blood volume in the normal subjects and hypertensive patients following the injection of phentolamine are illustrated in Fig. 8 and 9, respectively. In all but one (K.J.) of the normal subjects and in all the hypertensive patients, the changes followed a similar biphasic pattern. The intravenous injection of the drug was immediately followed by an increase in the cardiopulmonary blood volume; the average increase at the end of the first minute after the injection was $40 \mathrm{ml} . / \mathrm{sq} . \mathrm{m}$. (range 19-53) and $26 \mathrm{ml} . / \mathrm{sq} . \mathrm{m}$. (range 8-53) in the normal and hypertensive groups, respectively. This initial increase was then invariably followed by a rapid fall in the cardiopulmonary blood volume which reached its maximum extent in all subjects between the third and fifth minutes after the injection. The average maximum reduction below the control resting values was $49 \mathrm{ml} . / \mathrm{sq} . \mathrm{m}$. (range 32-87) and $68 \mathrm{ml} . / \mathrm{sq} . \mathrm{m}$. (range 40-100) in the normal and hypertensive groups, respectively. Subsequently, the cardiopulmonary blood volume returned towards pre-injection control values, though the time course of this return was very varied between different subjects. At the end of the period of observation, 30 minutes after the phentolamine injection, control values had been attained in all but one (K.J.) of the normal subjects, though in 3 (E.B., J.W., and J.N.) of the hypertensive patients it was still appreciably reduced.

Interrelationship of Changes in Central Vascular Pressures, Flow, and Volume. An example of these changes in one of the normal subjects and one of the hypertensive patients is illustrated in Fig. 10. It will be seen that the acute injection of phentolamine was immediately followed by a reduction in the pulmonary differential pressure $(\Delta \mathrm{P})$ at a time when there was a considerable increase in pulmonary blood flow. Such an increase in blood flow without an associated increase in $\Delta \mathrm{P}$ could only have been accommodated by an increase in pulmonary vascular capacitance. An appreciable increase in pulmonary blood volume was, in fact, apparent at the end of the first minute. This increase in pulmonary blood volume during the first minute after the injection of the drug may possibly explain the slightly delayed fall in the pulmonary arterial and wedge pressure compared with the more rapid reduction in the systemic blood pressure. Further, the immediate increase in pulmonary blood volume must, likewise, imply some inequality in forward output of the two ventricles during the first minute after injection of the drug.

The rapid fall in right atrial pressure, at a time when venous return was rapidly increasing, similarly points to a considerable increase in systemic venous capacitance. The relatively small shift of blood from the systemic to the pulmonary circulations could possibly have only accounted for a very small and transient fall in right atrial pressure if, in fact, there was any reduction at all in systemic venous volume.

Changes in Systemic and Pulmonary Arterial Blood Oxygen Saturations. The injection of phentolamine had no appreciable long-lasting effect on the oxygen saturation of the systemic arterial blood in either group of subjects. In the 6 normal subjects, the average arterial saturation before, and 30 minutes after, the drug was 93.8 per cent (range 92.9-94.5) and 93.5 per cent (range 


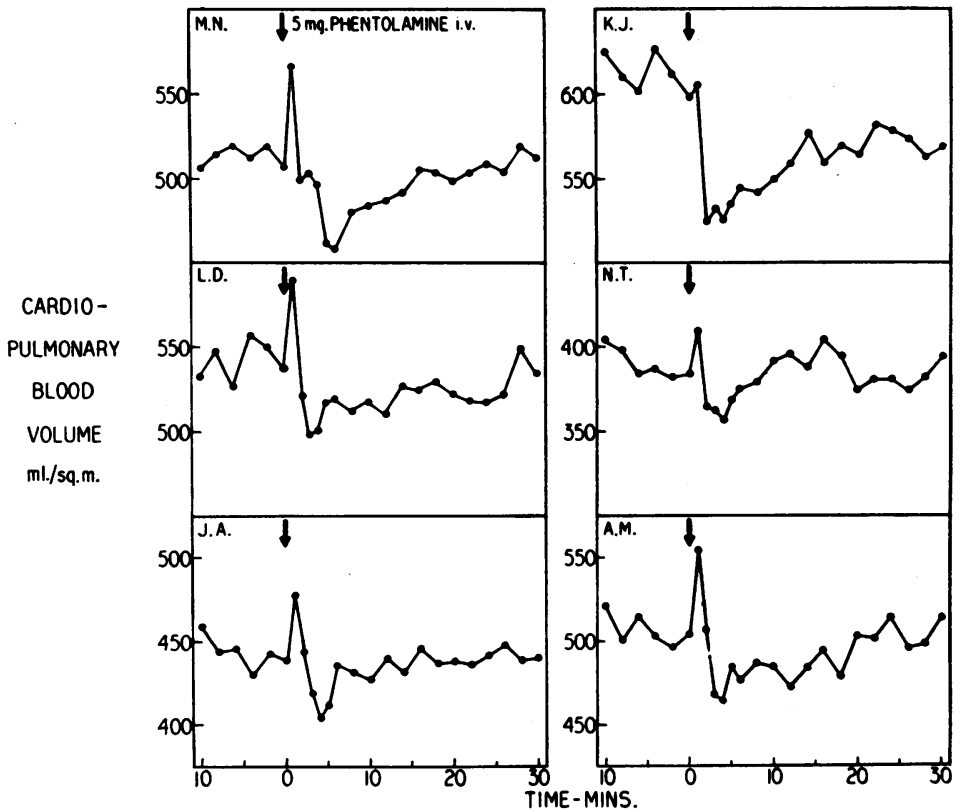

Fig. 8.-The effect of the intravenous injection of $5 \mathrm{mg}$. phentolamine on the cardiopulmonary blood volume of 6 normal subjects.

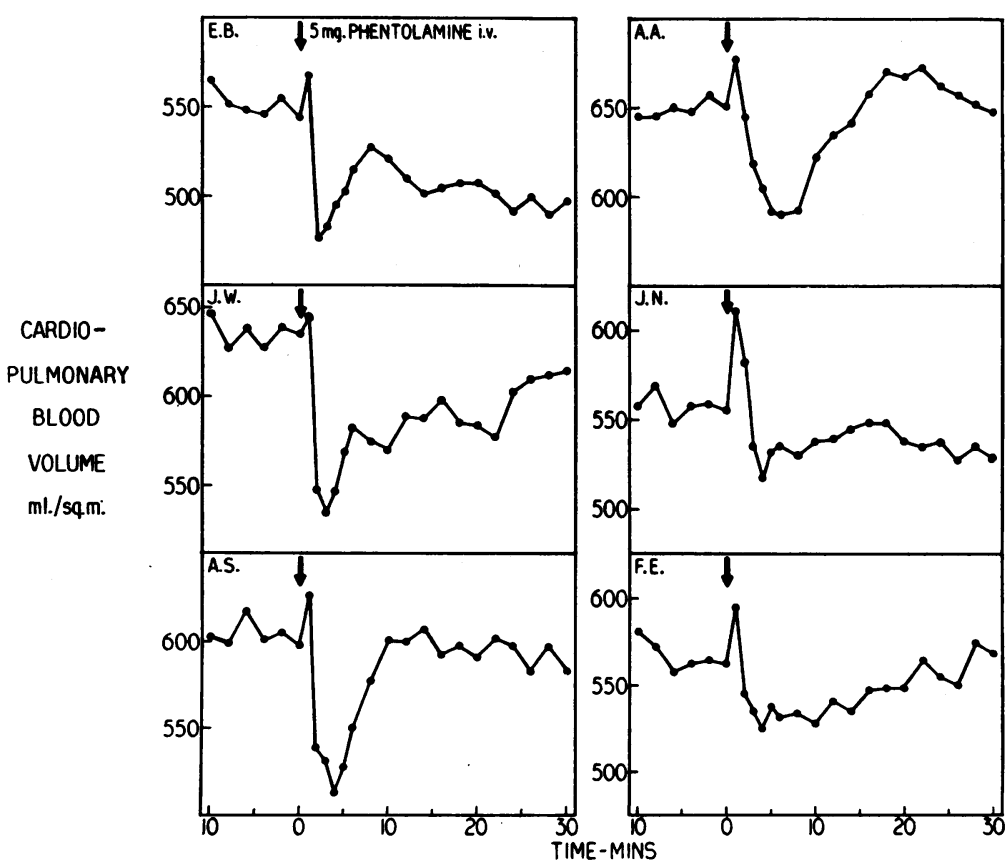

FIG. 9.-The effect of the intravenous injection of $5 \mathrm{mg}$. phentolamine on the cardiopulmonary blood volume of 6 hypertensive subjects. 


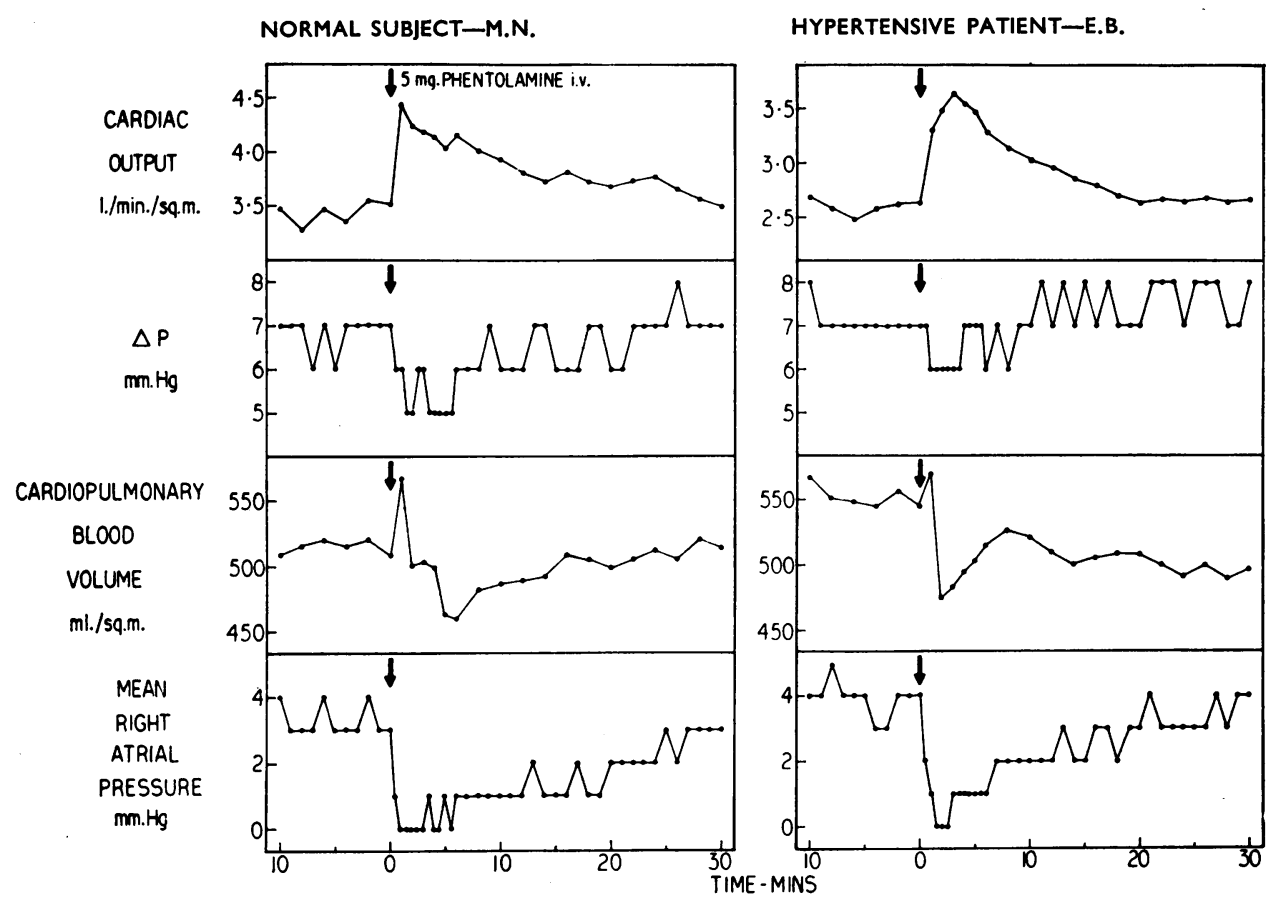

FIG. 10.-The interrelation of changes in central vascular pressures, flow, and volume following the acute intravenous injection of phentolamine.

92.5-95.0). The corresponding values in the 6 hypertensive patients were $93 \cdot 2$ per cent (range 92.2-94.1) and $93 \cdot 0$ per cent (range $91 \cdot 9-94 \cdot 2$ ).

Changes in the oxygen saturation of the pulmonary arterial mixed venous blood were much more marked. The injection of phentolamine was followed in all instances by an immediate increase in the oxygen saturation which reached its maximum value at the second or third minutes after the injection in all but 2 of the 12 subjects. In these 2 subjects (L.D. and N.T.) the maximum increase in the mixed venous blood was seen at the end of the first minute after the drug. The average maximum increase in the pulmonary arterial blood oxygen saturation was $7 \cdot 3$ per cent (range of increase $3 \cdot 7-10 \cdot 9$ ) in the normal subjects and $7 \cdot 4$ per cent (range of increase $5 \cdot 2-9 \cdot 1$ ) in the hypertensive subjects.

The systemic arterial blood oxygen capacity showed a small but consistent fall throughout the period of the investigation. Comparing the control values with those at the end of the period of observation, the average reductions were 0.45 vol. per cent (range of reduction $0.12-0.57$ ) and 0.44 vol. per cent (range of reduction $0.14-0.74$ ) in the normal and hypertensive groups of subjects, respectively.

Considered together these changes represent a rapid and significant reduction in the arteriovenous oxygen content difference ( $\mathrm{A}-\mathrm{V}$ diff.) following injection of the drug. The average maximum reduction in A-V difference in the 6 normal subjects was 1.410 vol. per cent (range of reduction $0.796-1.978$ ) and in the 6 hypertensive patients 1.481 vol. per cent (range of reduction 1.217-1.789).

\section{Discussion}

Previous reports of the pulmonary vascular effects of drugs that supposedly block the circulatory actions of endogenous circulating catecholamines have yielded irreconcilable conclusions (Dresdale, Schultz, and Michtom, 1951; Dresdale, Michtom, and Schultz, 1954; Braun, Izak, and 
Rosenberg, 1957; Mackinnon, Vickers, and Wade, 1956; Storstein et al., 1957; Rudolph et al., 1958). It is probable, however, that the conflict between these findings is due, not only to the diversity of the techniques used and the very different experimental designs employed, but also in no small part to the quite heterogeneous groups of patients studied. In the present study, the findings are clear cut. The intravenous injection of phentolamine resulted in a prompt reduction, not only of the pulmonary vascular pressures, but also of the pulmonary differential pressure gradient, at a time when the pulmonary blood flow and pulmonary blood volume were both rapidly increasing. These increases in pulmonary blood flow and blood volume, in the presence of a decreased pulmonary pressure gradient, could only have been accommodated in the pulmonary vascular bed by a considerable increase in its vascular volume distensibility or capacitance. Whether this increase was obtained by the dilatation of already open channels, or by the reopening of temporarily closed small vessels, or by a combination of both mechanisms is unknown. Although the pulmonary vasodilatation that followed the injection of phentolamine may well have increased blood flow in lung segments with poorly ventilated alveoli, any resultant small decrease in pulmonary venous and hence systemic arterial saturation would almost certainly have been obscured by the rapid rise in saturation of the mixed venous blood resulting from the increased systemic blood flow and reduced oxygen uptake of the tissues (Taylor et al., 1965d).

How these pulmonary vascular changes are brought about is uncertain, though certain observations are of interest. Exogenously administered catecholamines are known to produce small but definite changes in the pulmonary circulation with an increase in the pulmonary vascular resistance (Patel, Lange, and Hecht, 1958; Taylor et al., 1965a). However, in all of these studies the changes in pulmonary resistance reported were quite small in spite of the relatively large amounts of catecholamines administered. In normal resting subjects, the level of circulating catecholamines is extremely small (Löfving and Mellander, 1956). It seems most unlikely, therefore, that any but a very small proportion of the changes observed could have been due to blockade of endogenous circulating adrenaline and noradrenaline. The evidence is even more conclusive with regard to the role of the sympathetic blocking activity of the drug on the pulmonary circulation. The administration of far more potent sympathetic blocking drugs has little or no vasodilator effect on the pulmonary circulation of normal subjects (Taylor and Donald, 1960; Harris, Bishop, and Segel, 1961; Taylor et al., 1962). It is unlikely that the weak sympathetic blocking activities of phentolamine (Walker et al., 1950; Taylor et al., 1965e, 1965f) would have any significant part to play in the changes observed. It must be concluded, therefore, that these were probably due to a direct effect of the drug on the pulmonary vessels. However, the evidence is not entirely derived by exclusion. The time course of the pulmonary vascular changes observed was so rapid that any other more direct mechanism is most unlikely. In addition, the catecholamine blocking effects of the drug are known to persist for much longer than the relatively evanescent effects observed in the present study (Taylor et al., 1965c). Finally, other parallel studies have demonstrated the direct action of the drug in relaxing the smooth muscle of the resistance vessels of the systemic circulation in both normal and hypertensive subjects (Taylor et al., 1965c, d, e).

Similar and equally valid arguments can be applied to the changes observed in the central venous pressure. Although there is little doubt that administered noradrenaline causes vigorous venous contraction (Fowler, et al., 1951; Burch and Murtadha, 1956; Folkow, Johansson, and Mellander, 1960; Rose et al., 1962), it seems unlikely that the extremely low levels of circulating catecholamines present in normal resting man play any but an entirely subordinate role in the maintenance of normal venous tone. In addition, the administration of sympathetic blocking drugs in man has rarely produced changes in central venous pressure of comparable magnitude to those observed in the present study (Taylor et al., 1962). It must be concluded, therefore, that the marked reduction in right atrial pressure at a time when venous return was appreciably increased was almost certainly due to a direct effect of the drug in causing venous dilatation.

These findings have a considerable bearing on the mechanism by which the drug produces its effects on the systemic blood pressure. The acute injection of phentolamine resulted in an immediate 
dilatation of the pulmonary vascular bed. The resulting increase in pulmonary vascular capacitance was associated with an immediate increase in the pulmonary blood volume. As the pulmonary and systemic blood volumes form a reciprocating system, and as it is most unlikely that the drug caused an acute increase in total circulating blood volume, the transfer of blood to the pulmonary circulation could only have been achieved at the expense of that in the systemic vascular bed. Further, as the drug caused a relaxation of the systematic arterial resistance vessels and also a considerable increase in systemic venous capacitance, it seems not unlikely that some, if not all, of the reduction in systemic blood volume took place from the systemic arterial circulation. Although it is impossible to assess the magnitude of this fall in systemic arterial blood volume, there is little doubt that it would seriously aggravate the immediate hypotensive potency of the drug.

The powerful, but quite non-specific, generalized vasodilatation produced by phentolamine unfortunately severely curtails its therapeutic usefulness in the treatment of pulmonary vascular disease. Hypertension in the lesser circulation due to valvular or myocardial disease of the left heart is invariably associated with compensatory vasoconstriction of the regional territories of the systemic circulation. In spite of the hæmodynamic benefits that may possibly result from any reduction in the pulmonary hypertension, the concomitant reduction in the systemic vascular resistance that would necessarily follow administration of the drug could prove, on occasion, to be extremely hazardous. Such events have been previously observed with the administration of priscoline (Mackinnon et al., 1956) and bretylium (Taylor and Donald, 1960) to patients with mitral valve disease in whom these adrenergic blocking drugs were administered in an attempt to lower the raised pulmonary vascular resistance. Similarly, phentolamine could be expected to be of little value against the pulmonary hypertension of chronic pulmonary parenchymal disease. However, the direct pulmonary vasodilator properties of the drug suggest its possible use in the treatment of primary pulmonary hypertension, though its practical usefulness in this respect is much reduced by the obligatory parenteral administration. Finally, though the use of the drug in patients with acute pulmonary œdema due to left ventricular failure secondary to hypertensive vascular disease does not appear to have been reported, its circulatory effects are such as to offer an immediate, powerful, and rational remedy for this cardiovascular emergency.

\section{SUMMARY}

Observations relating to the circulation have been made on 6 normal subjects and 6 hypertensive patients before and after the acute intravenous injection of $5 \mathrm{mg}$. phentolamine.

The drug caused a prompt reduction in the pulmonary arterial and wedge pressure, in the pulmonary pressure gradient, in the pulmonary vascular resistance, and in the right atrial and systemic arterial pressures; the cardiac output was invariably increased.

Evidence is presented that the predominant vascular activity of the drug is to cause a direct relaxation of the vascular smooth muscle, affecting not only the systemic resistance vessels, but also the pulmonary and systemic venous circulations. This direct effect of the drug appears to be far more potent than its antagonism of the effects of circulating catecholamines or its very much weaker sympathetic blocking action.

The injection of phentolamine was also immediately followed by a transient small increase in the cardiopulmonary blood volume. It is suggested that this transfer of blood occurs predominantly from the systemic arterial circulation potentiating the direct hypotensive effect of the drug resulting from systemic vasodilatation.

The authors wish to thank Professor K. W. Donald for the facilities offered and his encouragement throughout. They are deeply indebted to Mr. J. Ramsay and technicians for technical assistance and to Sister M. G. Mitchell and nursing staff for invaluable help during the investigations. The authors also wish to express their appreciation to the Medical Research Council, Moray Endowment Trust, the Board of Management of the Royal Infirmary, and Ciba Laboratories Ltd., for financial support with the investigation. Phentolamine was supplied by Ciba Laboratories Ltd., Horsham, England. 


\section{REFERENCES}

Braun, K., Izak, G., and Rosenberg, S. Z. (1957). Pulmonary arterial pressure after priscoline in mitral stenosis. Brit. Heart J., 19, 217.

Burch, G. E., and Murtadha, M. (1956). A study of the venomotor tone in a short intact venous segment of the forearm of man. Amer. Heart J., 51, 807.

Dresdale, D. T., Michtom, R. J., and Schultz, M. (1954). Recent studies in primary pulmonary hypertension including pharmacodynamic observations on pulmonary vascular resistance. Bull. N.Y. Acad. Med., $20,195$.

—- Schultz, M., and Michtom, R. J. (1951). Primary pulmonary hypertension; clinical and hemodynamic study. Amer. J. Med., 11, 686.

Fisher, R. A. (1946). Statistical Methods for Research Workers, 10th ed. Oliver and Boyd, Edinburgh.

Folkow, B., Johansson, B., and Mellander, S. (1960). A comparison of the effects of noradrenaline and angiotensin on the resistance and the capacitance vessels in cats. Acta physiol. scand., 50, Suppl. 174, p. 50.

Fowler, N. O., Westcott, R. N., Scott, R. C., and McGuire, J. (1951). The effect of nor-epinephrine upon the pulmonary arteriolar resistance in man. J. clin. Invest., 30, 517.

Harris, P., Bishop, J. M., and Segel, N. (1961). The influence of guanethidine on hypoxic pulmonary hypertension in normal man. Clin. Sci., 21, 295.

Löfving, B., and Mellander, S. (1956). Some aspects of the basal tone of the blood vessels. Acta. physiol. scand., 37,134

Mackinnon, J., Vickers, C. F. H., and Wade, E. G. (1956). The effects of adrenergic-blocking agents on the pulmonary circulation in man. Brit. Heart J., 18, 442.

Patel, D. J., Lange, R. L., and Hecht, H. H. (1958). Some evidence for active constriction in the human pulmonary vascular bed. Circulation, 18, 19.

Rose, J. C., Kot, P. A., Cohn, J. N., Fries, E. D., and Eckert, G. E. (1962). Comparison of effects of angiotensin and norepinephrine on pulmonary circulation, systemic arteries and veins, and systemic vascular capacity in the dog. Circulation, 25, 247.

Rudolph, A. M., Paul, M. H., Sommer, L. S., and Nadas, A. S. (1958). Effects of tolazoline hydrochloride on circulatory dynamics of patients with pulmonary hypertension. Amer. Heart J., 55, 424.

Storstein, O., Elgvin, T., Helle, I., and Sebelien, J. (1957). The effect of phentolamine on the pulmonary circulation. Scand. J. clin. Lab. Invest., 9, 150.

Taylor, S. H., and Donald, K. W. (1960). The circulatory effects of bretylium tosylate and guanethidine. Lancet, 2, 389.

- - George, M., McDonald, A., and Staunton, H. P. (1965a). The effects of noradrenaline and angiotensin on the systemic and pulmonary circulations in man. To be published.

--, Kennelly, B. M., MacKenzie, G. J., Sutherland, G. R., Hutchison, D. C. S., Staunton, H. P., and Donald, K. W. 1965b). A comparison of the direct Fick and dye dilution methods of measurement of the cardiac output in man. In preparation.

—, MacKenzie, G. J., Staunton, H. P., George, M., McDonald, A., and Donald, K. W. (1965c). The circulatory effects of phentolamine during noradrenaline and angiotensin infusion in man. Brit. J. Pharmacol. In the press.

- -, Sutherland, G. R., Hutchison, D. C. S., Kidd, B. S. L., Robertson, P. C., Kennelly, B. M., and Donald, K. W. (1962). The effects of intravenous guanethidine on the systemic and pulmonary circulations in man. Amer. Heart J., 63, 239.

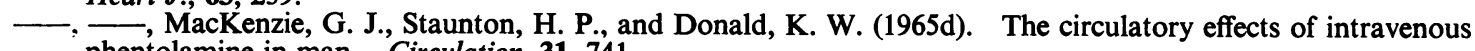
phentolamine in man. Circulation, 31, 741.

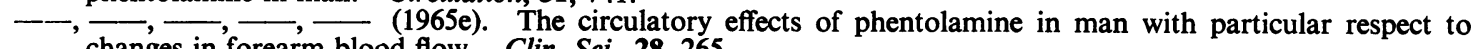
changes in forearm blood flow. Clin. Sci., $28,265$. $-\frac{1}{\operatorname{man}}, \frac{}{\text { Clin. }}, \frac{}{S c i}, \frac{1}{28,117}$.

Walker, H. A., Heymans, C., Wilson, S., and Richardson, A. P. (1950). The effect of C-7337 on carotid sinus reflex and on pressor and peripheral vascular actions of epinephrine and nor-epinephrine. J. Pharmacol. exp. Ther., 98, 33. 